ARTIGO

http://dx.doi.org/10.21721/p2p.2017v4n1.p109-129

\title{
BIBLIOTECÁRIOS EM HOSPITAIS: PRÁTICAS INFORMACIONAIS ${ }^{1}$
}

\author{
Marcio S. Finamor \\ Programa de Pós-Graduação em Ciência da Informação IBICT/UFRJ \\ marciofinamor@gmail.com \\ Clovis R. Montenegro de Lima \\ Instituto Brasileiro de Informação em Ciência e Tecnologia - IBICT \\ clovismlima@gmail.com
}

\begin{abstract}
Resumo
Discute-se a inserção e as práticas informacionais dos bibliotecários nas equipes multiprofissionais de saúde em hospitais. Tomando-se como referência o modelo bem-sucedido do sistema de saúde canadense, em que bibliotecários agem na equipe de forma rotineira: prática inexistente no Brasil. Busca conferir as atividades e competências, desenvolvidas por bibliotecários médicos, a fim de configurar uma nova proposta de trabalho. Constitui uma abordagem qualitativa pela amostragem por conveniência, selecionando especialistas como: profissionais da informação, médicos e profissionais de saúde convidados a discutir as perspectivas de agir e desafios. Conclui-se que as perspectivas de agir são promissoras e emergentes, mas que requerem uma reconfiguração na formação do bibliotecário e a aquisição de novas competências, assim como a criação de eixos sobre informação em saúde e ciências da saúde em sua formação.
\end{abstract}

Palavras-chave: Bibliotecário em Hospitais. Bibliotecários médicos canadenses. Agir do Bibliotecário. Competências.

\section{LIBRARIANS IN HOSPITALS: INFORMATION PRACTICES}

\begin{abstract}
I discussed the insertion and informational practices of librarians in multiprofessional health teams in hospitias. Taking as reference the successful model of the Canadian health system, in which librarians act in the team routinely: a practice that does not exist in Brazil. It seeks to check the activities and skills developed by medical librarians in order to set up a new job proposal. It is a qualitative approach by sampling for convenience, selecting specialists such as: information professionals, physicians and health professionals invited to discuss the prospects for action and challenges. It is concluded that the perspectives of action are promising and emerging, but that require a reconfiguration in the formation of the librarian and the acquisition of new competences, as well as, the creation of axes on information in health and health sciences in their formation.
\end{abstract}

Keywords: Librarian in Hospitals. Canadian medical librarians. Act of the Librarian. Skills.

\section{Introdução}

Este artigo tem como objetivo verificar as práticas do agir do bibliotecário nas organizações de saúde dentro das equipes multiprofissionais em hospitais. Tomando-se como referência um conjunto de ações, modelos e práticas de bibliotecários médicos ou

\footnotetext{
${ }^{1}$ Artigo elaborado a partir da parte prática da dissertação de FINAMOR, M. S. intitulado: "O Agir Comunicativo e Crítico do Bibliotecário nas Organizações de Saúde”. Instituto Brasileiro de Informação em Ciência e Tecnologia - IBICT/UFRJ.
} 
bibliotecários clínicos (canadenses), a fim de trazer para o Brasil e, para a classe dos profissionais, novos horizontes, efetivas ações e contribuições na rede de equipe médica, a partir de um olhar acurado e crítico da profissão na Sociedade da Informação.

A escolha deste caminho se dá por vários motivos, dentre eles está o legado existente na cultura canadense - em hospitais públicos - da existência de Bibliotecários dentro da equipe multiprofissional em saúde no apoio ao desenvolvimento de protocolos médicos. Esse profissional trabalha junto com enfermeiros, psicólogos, médicos e terapeutas, isto é, com a equipe em geral, da rede de saúde, em suas respectivas áreas médicas, assim como com os pacientes. Os bibliotecários fazem parte das equipes multiprofissionais dos hospitais, como uma presença rotineira na equipe, utilizando e criando serviços de informação ${ }^{2}$ nesses ambientes, coletando informações de pacientes, para o apoio e a tomada de decisão dos médicos, fazendo pesquisas médicas e coletando evidências médicas em diferentes e relevantes suportes. Nas palavras da pioneira bibliotecária médica Gertrude Lamb (19182015):

Meu trabalho envolve realmente sair da biblioteca, ir até as enfermarias para ver os médicos, enfermeiros, fisioterapeutas, terapeutas ocupacionais e outros profissionais de saúde fazendo o trabalho deles. Onde eles têm uma decisão a tomar em relação um paciente, eles são esperados para usar informações de "evidência baseada". É aí onde eu entro. Posso ajudar a encontrar as evidências para eles basearem em suas decisões. Porque já estive em enfermarias e as reuniões, eu tenho um entendimento do que é que querem saber e para que possa voltar para o escritório e usar os bancos de dados médicos temos acesso para encontrar artigos atualizados e pesquisas. (HLWIKI, 2016) ${ }^{3}$.

A rede de hospitais canadense percebeu a importância e o valor de se ter um profissional especialista em informação (o bibliotecário) em sua equipe, seja no apoio aos médicos na tomada de decisão clínica ou no cuidado de pacientes individuais, seja na prestação de serviços de saúde específica ou do público em geral. O trabalho desse profissional baseia-se em suas funções, habilidades e competências aprendidas na sua formação básica como: coleta de informações relevantes, pesquisa, organização, interpretação, armazenamento, recuperação, filtro das informações, disseminação e o

\footnotetext{
${ }^{2}$ Segundo o dicionário de Biblioteconomia serviços de informação são interfaces e setores cuja função básica é fornecer informações relativas aos respectivos acervos, banco de dados e a interlocução, bem como torná-los acessíveis aos usuários, clientes, agentes de saúde, pacientes e profissionais em geral que tenham suas necessidades informacionais de cunho profissional ou pessoal atendidas pelas ferramentas tecnológicas ou movimentação física da informação (CUNHA; CAVALCANTI, 2008, p. 334). Esses serviços podem ser: Disseminação Seletiva da Informação (DSI); Mediação da Informação; Uso de aplicativos e redes sociais; Agregadores de Informação (RSS); Redes Colaborativas: Wiki, dentre outras. ${ }^{3}$ As citações usadas como HLWIKI, foram retiradas da plataforma, com tradução nossa e seus respectivos anos representam a última atualização feita na página.
} 
tratamento da informação de forma sistemática e estruturada, possibilitando a maximização de seu uso.

Além dessa certificação, foi constatado que o bibliotecário nas equipes multiprofissionais aumentou o ganho para a saúde, o ganho econômico em um sistema público, aumentou a eficácia no sistema e no apoio às práticas médicas, sendo esse profissional denominado no Canadá de bibliotecário médico, clínico ou saúde. Outro fator expressivo é que os médicos têm роисо tempo para analisar a quantidade de informação e evidências médicas disponíveis em seus vários suportes e meios para tomar decisões em um curto espaço de tempo, como já evidenciado por autores como: (CIOL; BERAQUET, 2009); (GOMES; VARELA, 2016); (HLWIKI, 2016). É nesse momento que o bibliotecário se destaca ao reduzir esse tempo e acelerar o processo de protocolos médicos e de tomada de decisão médica com base em evidências. Bibliotecários de saúde podem economizar tempo de clínicos em busca de informações para os pacientes e "consumidores" de informação em saúde, justificando a necessidade de sua inclusão nas equipes de saúde, cuja presença aqui no Brasil é inexistente.

O caminho metodológico foi o da abordagem qualitativa pela amostragem por conveniência, onde selecionamos especialistas e membros da população mais acessíveis no momento para discutir e responder o questionário. Profissionais especialistas em informação em saúde e da medicina, bem como profissionais e pesquisadores especialistas em informação que possuem conhecimento e convivência com a realidade e com o assunto em questão. Além da busca na literatura canadense - pelas bases de dados, portais de Biblioteconomia na área da saúde ${ }^{4}$ canadense e revistas específicas da área - verificando o que existe de exemplos, ações e práticas do profissional bibliotecário em organização de saúde canadense e na experiência internacional.

\section{Bibliotecário Médico e Informação em Saúde: práticas canadenses}

Um bibliotecário clínico, ou bibliotecário médico, no entendimento da ação desse profissional, fornece serviços de biblioteca especializada em hospitais e outras organizações

\footnotetext{
${ }^{4}$ Utilizamos a plataforma HLWIKI ${ }^{4}$ Internacional, que é uma enciclopédia global com dez (10) portais de Biblioteconomia na área da saúde, com artigos e diversos meios de comunicação social e uma gama de tópicos de tecnologia de informação, com a curadoria de uma equipe de bibliotecários de saúde internacionais; plataforma essa administrada e criada pelo bibliotecário médico Dean Giustini. Contém (1100) páginas de informações sobre bibliotecários médicos, práticas e iniciativas com suas respectivas fontes $\mathrm{e}$ hipertextos. Link da plataforma: http://hlwiki.slais.ubc.ca /index.php/HLWIKI_International
} 
de saúde através da participação em atividades clínicas no ciclo com os profissionais de saúde. Ao trabalhar de perto com equipes atribuídas dos clínicos (estudantes, residentes, médicos e outros), um bibliotecário-clínico pode responder às necessidades de informações que surgem em situações dentro da clínica. Já que estão fora da biblioteca, bibliotecáriosclínicos facilitam ainda mais o acesso à literatura médica para responder perguntas clínicas para a maioria dos profissionais de saúde, pois executam, mediam e treinam os usuários através do processo de pesquisa e de localizar as melhores evidências médicas da literatura. Biblioteconomia clínica é definida como uma abordagem proativa dos bibliotecários no apoio da medicina baseada em evidências, na prática clínica, fornecendo para os médicos altamente e especificamente informações e registros de qualidade sintetizada e estruturada, centrados na cientificidade da medicina e no paciente (HLWIKI, 2014).

O trabalho dos bibliotecários médicos e de profissionais de saúde é intenso e em geral esses profissionais atuam em diversas instituições, fazendo uso de serviços de informação, processos e das tecnologias para melhoria da assistência médica, buscando o bom atendimento e precisão nos diagnósticos com uso de : de bibliotecas acadêmicas de saúde, bibliotecas especializadas, redes de revistas científicas, banco de dados da área médica e ambiente hospitalar, além de outras bibliotecas especiais e recursos informacionais da área de saúde. Muitos membros trabalham em equipes, incorporados como peritos especialistas em informações, pesquisadores e bibliotecários clínicos ou médicos. Bibliotecários de saúde gerenciam, disseminam e mediam serviços de biblioteca e serviços de informação dentro de suas organizações. Esses profissionais aventuram-se em clínicas, indo além de suas áreas tradicionais, dado que, na era da informação, existem demandas por bibliotecários médicos em enfermarias e durante as rondas clínicas (HLWIKI, 2015, 2016).

No crescimento dessa área, a Biblioteconomia clínica, como é denominada no Canadá, apresenta-se como inovação imprescindível nesse campo de conhecimento, pois é uma área tradicional de agir dos bibliotecários-clínicos, em equipes de serviços clínicos, estando incumbidos de envolver-se com as equipes médicas e pacientes para a prestação de serviços de informações baseadas em evidências médicas. Os proponentes da Biblioteconomia clínica são conhecidos por uma variedade de títulos de posição, tais como bibliotecários clínicos ou bibliotecários médicos, e praticam uma forma de Biblioteconomia incorporada, como discutiremos a seguir (HLWIKI, 2014).

Com o objetivo de fornecer informações íntegras e fatos aos consumidores de informação sobre a própria saúde, os bibliotecários médicos destinam-se à educação do paciente para explicar os exames, testes e tratamentos, e visam aumentar a consciência global 
das questões de saúde e bem-estar. Informação sobre a saúde do consumidor, muitas vezes, é fornecida sem interpretação por prestadores de saúde. Os consumidores de saúde distinguemse dos pacientes por não necessariamente buscarem informações com base em uma queixa específica, ou doença, muitas vezes procuram aumentar o total bem-estar nas habilidades da alfabetização de saúde, como também buscam se concentrar na promoção da saúde e em aprender como navegar no sistema de cuidados de saúde com êxito (HLWIKI, 2016).

Dentre as habilidades dos bibliotecários médicos canadenses, umas dessas práticas fundamentais é a:

\begin{abstract}
Alfabetização de saúde permite que o público e o pessoal que trabalha em todos os contextos relacionados com a saúde para encontrar, entender, avaliar, comunicar e usar a informação em saúde. Alfabetização de saúde é o uso de uma ampla gama de habilidades que melhoram a capacidade das pessoas para agir na informação para viver vidas mais saudáveis. Essas habilidades incluem leitura, escrita, ouvindo, falando, aritmética e análise crítica, bem como habilidades de comunicação e interação. (HLWIKI, 2016, grifo nosso).
\end{abstract}

Os bibliotecários médicos canadenses, no agir da alfabetização de saúde, são reconhecidos como os determinantes da saúde no sistema de saúde do Canadá. Em uma sociedade multicultural como a do Canadá, a cultura é um fator importante na determinação se os pacientes compreendem as informações de saúde que lhes são apresentadas (HLWIKI, 2016). Portanto, é crucial a integração de bibliotecários na equipe médica, ainda mais no Brasil, que também é um país multicultural, com diversidades culturais, de gêneros e etnias.

Dentre as principais atividades dos bibliotecários médicos canadenses, podemos destacar as:

- Rodadas com equipes clínicas, participação na manhã de relatórios; responder às necessidades de informações expressas ou de maneira antecipada;

- Realização de pesquisas com especialistas da literatura médica para responder perguntas e questões relacionadas com o atendimento ao paciente;

- Fornecimento individualizado, ponto de necessidade de instrução para residentes e estudantes na busca de banco de dados;

- Apresentação de tópicos de interesse para a equipe clínica (por exemplo, formando uma pergunta de pesquisa, estratégias de pesquisa avançada);

- Moldar os serviços de conscientização para manter a equipe atualizada e de antecipação das áreas de interesse e,

- Lê, avalia, resume e destaca os pontos relevantes da literatura para a equipe 
(HLWIKI, 2016).

Na prestação de serviços de referência no âmbito da saúde, bibliotecários devem aterse na questão do:

Comunicar com clareza seu papel como bibliotecário de saúde para pacientes e médicos; Nunca diagnosticar (ou ajudar a diagnosticar um paciente); Considere as opções de privacidade para demonstração, ou assumir tópicos neutros; Verificar fontes independentes, para reduzir o viés de sugerir; Encontrar recursos canadenses (ou no Brasil) de contexto, sempre que possível; Fornecer um folheto de competências de avaliação; Consulte perguntas aos profissionais de saúde para verificação; Considere comportamentos de busca de informações e necessidades de informação do paciente; Considere variáveis (quem está doente, o que é a doença) e selecione informações em conformidade; Nível de alfabetização de saúde deve sempre ser considerado; Inquirir sobre a linguagem e conforto com tecnologia; Os requerentes de informações básicas necessitam de panfletos sobre fatos, sintomas e tratamentos; Sobre informações avançadas requerentes querem pesquisas detalhadas, relatórios e informações de julgamento de clínicas; Busca de informações em populações especiais, o que inclui pacientes de saúde mental, buscando informações na tentativa de tentar minimizar o estigma e a vergonha. (HLWIKI, 2015).

Algumas atividades típicas, nas quais os bibliotecários de saúde devem se envolver nas equipes médicas, são:

Consultas preliminares com médicos, clínicos, pesquisadores; Aconselhando sobre partes do processo de revisão sistemática; A construção de estratégias de busca (bancos de dados, recursos, palavras-chave, termos controlados); Técnicas de busca estendida, procurando literatura; A recolha e gestão de documentos de texto completo e citações; Assessoria na seleção de software para uma revisão sistemática; Avaliação crítica da literatura; Extraindo dados de literatura selecionada; Seção de metodologia de revisão da literatura escrita; Revisão de projeto ou artigo completo antes da apresentação; Atualizando informações coletadas e metodologia conforme necessário. (HLWIKI, 2015).

As exaustivas pesquisas da literatura médica sempre foram uma parte importante do processo de revisão sistemática da literatura ${ }^{5}$ do assunto. No entanto, foi preciso uma década

\footnotetext{
${ }^{5}$ A revisão sistemática da literatura é um meio de identificar, avaliar e interpretar todas as pesquisas disponíveis relevantes para uma questão de pesquisa específica, ou área temática, ou fenômeno de interesse. Estudos individuais que contribuem para uma revisão sistemática são chamados de estudos primários; a revisão sistemática é uma forma de estudo secundário (KITCHENHAM, 2004, p. 1, tradução nossa).
} 
ou mais para os investigadores dependerem de bibliotecários médicos e de seus conhecimentos de pesquisa e métodos. Para o quesito revisão sistemática, identificamos na literatura habilidades e experiências que são mencionadas como indispensáveis para o processo de busca na literatura médica e na necessidade informacional do campo da saúde:

1. Habilidade de especialista em pesquisa é uma parte crítica da realização de uma revisão sistemática bem projetada;

2. Pesquisa abrangente de todos os bancos de dados relevantes para estudos o que inclui inéditos de literatura;

3. A documentação de estratégias explícitas é essencial para a reprodutibilidade;

4. Bibliotecários de saúde desempenham um papel-chave no processo, incluindo consultoria em alguns projetos como coinvestigadores e coautores;

5. Outras funções definidas incluem treinador de pesquisa de literatura, pesquisador especialista, documentalista do processo de busca, gerenciador de referência, credor entre bibliotecas e fornecedor do documento, além de relatar informações (HLWIKI, 2016).

Essas listas de competências em referência médica são parte de uma dinâmica das competências para os bibliotecários de saúde que combina e reconhece os mais importantes conhecimentos, competências e habilidades técnicas para o sucesso no campo da medicina. Embora várias competências estejam firmemente enraizadas nas tradições do bibliotecário e dos afazeres na biblioteca, que datam de meados do século $\mathrm{XX}$, ou antes, a lista apresentada a seguir tem como objetivo colocar competências tradicionais em um contexto mais atual.

Dentre as funções dos bibliotecários citadas na plataforma HLWiki, resumidamente e diante da quantidade de exemplos e modelos práticos e teóricos desconhecidos por esses profissionais aqui no Brasil, estão: além de trabalhar na equipe médica para o apoio à tomada de decisão dos médicos, para o apoio à consecução de protocolos médicos, para a ajuda aos pacientes no consumo de informação em saúde e acesso ao conhecimento sobre informações médicas e sua condição de saúde, outro fator que requer atenção e um olhar do porvir, por parte dos bibliotecários e da prestação de serviços informacionais na área da medicina, é:

- serviços informacionais oferecidos pelos hospitais canadenses adjuntos à biblioteca de ciências da saúde são úteis no atendimento ao paciente, em reabilitação, na saúde comunitária e pública, nos cuidados de longo prazo e nos cuidados domiciliários. Sobre o atendimento ao paciente a investigação dos impactos imediatos: "[para] um guia sobre a utilização de equipamentos de monitoramento", "papéis e escopo da prática de enfermeiros", 
"aprimorando o conhecimento [do paciente] sobre sua condição" e "fornecendo informações para um novo procedimento" (FARRELL; MASON, 2014).

- atendimento aos pacientes e médicos bibliotecários na assistência ao paciente e aos médicos em que: fazem diversas pesquisas para nosso relatório da manhã no hospital. Eles vêm às nossas rodadas pediátricas semanais, coletando e disseminando informações quase em tempo real. Além de direcionar o atendimento ao paciente, é indiscutível o valor do bibliotecário nas habilidades de pesquisar: tenho usado o bibliotecário para pesquisas avançadas para projetos científicos e ele certamente facilita a minha capacidade de ter mais dados completos. Os bibliotecários têm sido muito proveitosos na divulgação de informação e no acesso a informações médicas para os nossos residentes. Para fazer uma pesquisa mais ampla e dar mais profundidade ao tópico, em vez de um paciente em particular. É útil porque podemos obter os dados de fundo para guiar a nossa melhoria de desempenho. Quando um bibliotecário age em sua função de informar, não é para ajudar um paciente em particular, é para ajudar uma categoria de pacientes em maiores números (MARSHALL et al., 2013).

- Revisões sistemáticas são uma metodologia de pesquisa crescente em muitos campos, não o menor dos quais inclui as ciências da saúde. Por muitos anos os pesquisadores viram a importância de colocar as evidências existentes em um formato mais sintetizado, não apenas para orientar a tomada de decisões médicas mas também para orientar o financiamento da pesquisa e desenvolver ferramentas para melhor educar o público sobre os padrões de prática. Para a prestação de assistência aos autores na busca de estudos para inclusão em suas revisões (pesquisas médicas, teses e dissertações). A gama de elaboração de estratégias de busca para as principais bases de dados bibliográficos envolve executar essas pesquisas em bancos de dados disponíveis, salvar resultados de busca e enviá-los aos autores e aconselhar estes sobre como executar buscas em outros bancos de dados e como baixar resultados em seu software de gerenciamento de referência (ROSS-WHITE, 2016).

- A web semântica (web 3.0), uma vez que ela faz com que os motores de busca tornem possível pesquisar em uma camada superior da web em menos de um segundo, enfrentando sérios problemas associados ao uso de motores de busca, se queremos manter uma aparência de controle sobre nossas atividades de pesquisa e recuperação (HLWIKI, 2015). Para o bibliotecário médico Dean Giustini, idealizador da plataforma Wlwiki, a web 3.0 nos levará de volta a alguns dos tempos perdidos e princípios da profissão (GIUSTINI, 2007, p. 1274).

- Bibliotecários em funções e ações no acontecimento de desastres: são fundamentais para mitigação de desastres, planejamento, resposta e recuperação. Membros da 
força de trabalho ligada a desastres incluem tanto os profissionais de saúde licenciados ou credenciados (enfermeiras, paramédicos, farmacêuticos, médicos etc.) quanto profissionais treinados ou licenciados adicionais (voluntários da comunidade, bombeiros, gerentes de emergência etc.), incluindo os bibliotecários. Esses profissionais auxiliam rapidamente os trabalhadores dos desastres, identificando, avaliando e divulgando informações. Além disso, os bibliotecários treinam equipes de emergência no uso de ferramentas de informação e no monitoramento das fontes de informação para apoiar a tomada de decisões pelos gestores de emergência (HLWIKI, 2015).

- Bibliotecários à procura de estatísticas em saúde: é árduo, meticuloso, multicanal, com excesso de pesquisas, o que pode ser devido ao fato de as estatísticas de saúde poderem referir-se a conjuntos de dados, tipos e formatos e uma gama de estatísticas epidemiológicas de utilização do pessoal de saúde. Muitas estatísticas de saúde em todo o mundo são agora de livre acesso e algumas são fáceis de encontrar através de motores. No entanto, especialistas em habilidades são necessários para saber quais sites são para as estatísticas e quais bancos de dados devem ser pesquisados em suas interfaces. As informações de estatísticas de saúde mais comuns solicitadas são: prevalência da doença nas populações, internações e procedimentos e estatísticas vitais, tais como nascimentos, mortes, casamentos e taxas de divórcio. A incidência de doenças dentro das populações inclui surtos de gripe, pandemias e morbidade e mortalidade (número de pessoas que morrem de certas doenças em relação ao total da população). Outras informações estatísticas comuns são a economia e os custos de cuidados de saúde, distribuição demográfica das doenças com base na origem étnica, gênero, status socioeconômico e educação (HLWIKI, 2016).

O sistema de saúde do Canadá como forma de encorajar a prática baseada em evidências inseriu um novo profissional em equipes clínicas: o bibliotecário médico treinado em ciência ou medicina, bem como na Ciência da Informação. Esse profissional tem um impacto positivo nos resultados de saúde para os pacientes e pode levar a economias de tempo para profissionais de saúde, - e no apoio a salvar vidas ${ }^{6}$ - bem como a mediação de

\footnotetext{
${ }^{6}$ Exemplo de profissionais especialistas em informação e pesquisas avançadas que podem muito bem salvar vidas. Em 2001 um caso de uma voluntária de 24 anos veio a óbito em teste e estudo de asma. A voluntária iniciou seu envolvimento na pesquisa, ela participou conforme delineado no protocolo, recebeu aproximadamente $1 \mathrm{~g}$ de hexametiono por inalação. Em breve apresentou tosse seca e sintomas gripais. Na semana seguinte houve redução da saturação arterial de oxigênio. Após esforço mínimo sua condição piorou, culminando na síndrome de dificuldade respiratória e insuficiência renal. Ela morreu duas semanas depois. Os funcionários do hospital aceitaram o incidente e começaram a trabalhar para determinar a causa exata do que tinha acontecido com a jovem. Foi requisitada uma investigação interna aprofundada. Entre os lapsos citados no relatório encontrava-se a revisão da literatura para o uso não aprovado pela Food and Drug Administration (FDA) do hexametônio. A ingestão do fármaco hexametônio foi documentada em pré-1966, tendo efeitos adversos. Infelizmente, a base de pesquisa da equipe o pré-1966 não era pesquisável na época através do banco de dados PubMed da medicina. Artigos que descrevem os riscos de hexametônio apareceram antes de 1966 foram encontrados por um bibliotecário que assumiu a pesquisa rigorosa da literatura, nesse caso, não foi encontrado através de uma pesquisa convencional em base de dados. As
} 
informação de qualidade e relevante para o diagnóstico e apoio às ações e decisões dos agentes de saúde, conforme apontam os autores (ZIPPERER, 2003); (MARSHALL et al., 2013); (FARRELL; MASON, 2014); (CAMPBELL; DORGAN, 2015); (ROSS-WHITE, 2016), e outros.

A inserção do bibliotecário na equipe de saúde e no sistema de saúde se dá não só no apoio às atividades da equipe de saúde e dos pacientes, mas também nos benefícios para o hospital em relação aos seus custos. O aprimoramento e as melhorias nas formas de acesso à informação, mediação e serviços informacionais para equipe médica e pacientes pouparamlhes tempo. A presença de bibliotecário no relatório da manhã foi positivamente correlacionada com a diminuição do tempo de permanência hospitalar e consequentemente dos encargos. O apoio desse profissional está associado aos recursos economizados e à redução de custos, na a economia de tempo de um profissional de saúde (SOLLENBERGER; HOLLOWAY, 2013).

Os médicos usam uma variedade de fontes de informação para resolver as suas necessidades de informação clínica incluindo: pessoal, clínicos conhecidos, colegas, resultados de testes, registros médicos impressos e digitais, conversas com os pacientes, inspeção visual, resumos estatísticos de dados de doenças e evidências encontradas em artigos e livros, embora não haja disparidade em relação ao ranking de uso de recursos por médicos, como livros de medicina e revistas médicas. Os médicos enfrentam vários obstáculos ao tentar responder à perguntas clínicas com provas. Eles incluem: o tempo necessário para encontrar informações, dificuldade em modificar a pergunta original; dificuldade em selecionar uma estratégia de pesquisa ideal; falha de um recurso aparentemente apropriado para cobrir o tema; incerteza em saber quando foram encontradas todas as evidências relevantes; e síntese inadequada de todas as evidências. Restrições de tempo são uma barreira-chave, enquanto o volume de informação médica é outro obstáculo. A presença de um bibliotecário na equipe facilitaria a busca de evidências para o apoio no tratamento e diagnóstico baseados na informação facilitada por um bibliotecário (FLYNN; McGUINNESS, 2010).

Contudo, incluir bibliotecários nas equipes de saúde exigirá cuidado e atenção ao fluxo de trabalho acerca do design organizacional e social. A presença de uma pessoa, especialista em informação, na equipe de especialistas de saúde pode afetar a dinâmica interpessoal no fluxo de comunicação e na atenção ao funcionamento do papel adequado de revisão interna deveria ter sido mais rigorosa na sua exigência de exame da evidência. Esse erro poderia ter sido evitado devido a um maior reconhecimento pelos clínicos do valor dos bibliotecários como participantes-chave nas pesquisas e na segurança médica (ZIPPERER, 2003, p. 218-219). 
cada um para otimizar o desempenho da equipe. A formação do bibliotecário deve também ser abordada com competências definidas, conhecimento clínico expandido e preocupações éticas relacionadas com a confidencialidade. Com as mudanças em curso na área da saúde, como resultado de informações, tecnologias, ciências da saúde, bibliotecas e bibliotecários podem desempenhar um importante papel por trazerem alta qualidade de informação médica baseada em evidências para o agente de saúde e ajudarem a tornar o atendimento ao paciente ao mesmo tempo eficiente e eficaz. No sistema de saúde, unidade de informação em saúde, cuidados de saúde e bibliotecários estão se adaptando à evolução das necessidades de informação dos médicos, de outros profissionais de saúde, de pesquisadores e pacientes, com rigorosa avaliação, desenvolvimento de novas competências e modernização da formação do bibliotecário na questão da informação em saúde e serviços (SOLLENBERGER; HOLLOWAY, 2013).

Esse quadro de competências, funções e modelos de agir dos bibliotecários médicos canadense parece-nos adequado para o profissional na atualidade e em novo campo de ação: dentro da equipe médica e da saúde. É possível identificar habilidades importantes para a categoria. Sobre esse alicerce, apoiados no fazer apreendido em sua formação, ao lidar com a informação, a organização, a busca e a apreensão dos serviços de informação e mediação: no apoio aos agentes de saúde e pacientes. A inserção do bibliotecário na equipe médica/saúde atuante conforme o modelo canadense para a nossa categoria profissional já é de grande proporção e avanço na emergente sociedade da informação e na informação sobre saúde no Brasil. Os profissionais médicos, a equipe de saúde, os bibliotecários e os pacientes, no convívio um com os outros, em suas individualidades vistas de todos os ângulos, devem ter um cuidado maior em todos os parâmetros para fazer um "bom trabalho" e um bom atendimento, clamando por maiores recursos comportamentais e mudanças assistenciais diante da existência de informações científicas que possam salvar vidas ${ }^{7}$.

\section{Discussão com Profissionais Especializados sobre o Bibliotecário na equipe de saúde}

No quadro abaixo, identificamos os membros respondentes do questionário e em

\footnotetext{
${ }^{7}$ Segundo o relato: "no período de 1918 a 1919 a gripe espanhola se espalhou pelo mundo inteiro, matando de 20 a 80 milhões de pessoas. De origem viral, não havia tratamento conhecido. Como veio, se extinguiu. Com o intuito de pesquisar meios de evitar uma nova catástrofe, a comunidade internacional das áreas médica e de saúde pública procurou por décadas algum vestígio biológico do vírus causador dessa enfermidade. Só depois de muito tempo, foi encontrada uma amostra de tecido humano infectado pelo vírus num hospital militar da Inglaterra. A partir desses vestígios estão sendo desenvolvidas pesquisas para se descobrir vacinas e meios de tratamento da gripe espanhola. As pesquisas em torno da amostra só se tornaram possíveis graças à preservação dos arquivos científicos, datados de 1916, daquele hospital militar" (DITADI, 2003 apud SAYÃO, SALES, 2012).
} 
seguida apresentamos e debatemos os dados qualitativos sobre as motivações e opiniões dos profissionais em questão, para uma o trabalho dos bibliotecários na equipe de saúde.

Quadro 1 - Identificação dos especialistas que responderam os questionários

\begin{tabular}{|c|c|}
\hline Especialistas & Instituição \\
\hline $\begin{array}{l}\text { Prof Dr Cassio Renato Montenegro de Lima } \\
\text { Doutor em Ciências na área de Cirurgia - USP }\end{array}$ & Proctologista, Cirurgião do Aparelho Digestivo - UFSC \\
\hline $\begin{array}{l}\text { Adriana Fontes Zimmermann } \\
\text { Doutora em Ciências Médicas pela - UFSC }\end{array}$ & Médico reumatologista - UFSC \\
\hline $\begin{array}{l}\text { João Paulo Lyra da Silva } \\
\text { Doutorado em Saúde Pública - FIOCRUZ }\end{array}$ & Universidade Federal do Rio de Janeiro - UFRJ \\
\hline $\begin{array}{l}\text { Prof. Ricardo Bezerra Cavalcante, PhD } \\
\text { Doutorado em Ciência da Informação - UFMG }\end{array}$ & $\begin{array}{l}\text { Núcleo de Estudos e Pesquisas em Avaliação e Gestão de Serviços de } \\
\text { Saúde (NEPAG) }\end{array}$ \\
\hline $\begin{array}{l}\text { Cícera Henrique da Silva } \\
\text { Doutorado em Sciences de } 1 \text { Information Et de } \\
\text { La Communication - França }\end{array}$ & Fundação Oswaldo Cruz - FIOCRUZ, Brasil \\
\hline $\begin{array}{l}\text { Adriana de Freitas Velloso } \\
\text { Doutora em Ciência da Informação - UFRJ. } \\
\text { Mestre em Saúde Coletiva - UERJ } \\
\text { Medicina pela Universidade Gama Filho }\end{array}$ & Medicatrix Naturae Serviços Médicos LTDA. \\
\hline $\begin{array}{l}\text { Mariângela Maia } \\
\text { Doutoranda em Ciência da Informação - UFRJ. } \\
\text { Mestrado em Odontologia - UFF. }\end{array}$ & Prof. Universidade Salgado de Oliveira - UNIVERSO. Odontologia \\
\hline $\begin{array}{l}\text { Aline Arboit } \\
\text { Doutora em Ciência da Informação - UNESP }\end{array}$ & Universidade da Amazônia - UNAMA, Brasil. \\
\hline $\begin{array}{l}\text { Prof. Rene Faustino Gabriel Junior } \\
\text { Doutorado em Ciência da Informação - UNESP }\end{array}$ & $\begin{array}{l}\text { Profissional de saúde com experiência em análise de projetos de } \\
\text { pesquisa no Comitê de Ética em Pesquisa (CEP) envolvendo novos } \\
\text { medicamentos, tratamentos e procedimentos. Como também, em fontes } \\
\text { de informação para embasamento dos pareceres de aprovação dos } \\
\text { estudos. }\end{array}$ \\
\hline $\begin{array}{l}\text { Alice Ferry de Moraes } \\
\text { Doutorado em Ciência da Informação - UFRJ }\end{array}$ & Fundação Oswaldo Cruz/ICICT, FIOCRUZ/ICICT. \\
\hline $\begin{array}{l}\text { Daniel Guzmán } \\
\text { Medicina pela UFRJ }\end{array}$ & UNIMED. \\
\hline $\begin{array}{l}\text { Harry Correa Filho } \\
\text { Medicina pela UFSC }\end{array}$ & $\begin{array}{l}\text { Médico do Instituto de Cardiologia. Professor de Cardiologia do curso } \\
\text { de medicina da Fundação de apoio a Educação, pesquisa e extensão } \\
\text { UNISUL. }\end{array}$ \\
\hline $\begin{array}{l}\text { Danielle Ribeiro de Moraes } \\
\text { Doutorado em Saúde Pública, FIOCRUZ }\end{array}$ & Médica, tecnologista em saúde pública da Fundação Oswaldo Cruz. \\
\hline $\begin{array}{l}\text { Antônio Andrade } \\
\text { Pós-doutorado em Administração pela } \\
\text { Universidade do Porto }\end{array}$ & Universidade Federal do Estado do Rio de Janeiro - UNIRIO \\
\hline $\begin{array}{l}\text { Ludmila dos Santos Guimarães } \\
\text { Doutorado em Ciência da Informação - UFRJ }\end{array}$ & Universidade Federal do Estado do Rio de Janeiro - UNIRIO \\
\hline
\end{tabular}

Fonte: elaborado pelo autor

Dividimos os questionários em duas partes. Primeiro com perguntas específicas para os Bibliotecários e Cientistas da Informação (profissionais da informação) e a outra com perguntas específicas para os Médicos e profissionais de saúde, as quais foram:

- o que pode ser feito no ambiente hospitalar para informar os médicos sobre seu trabalho e demanda: 
$>$ "no âmbito de um hospital o bibliotecário precisa buscar maior aproximação com as equipes médicas e de pesquisa. Para o bibliotecário que trabalha em um hospital existem muitas áreas que seu trabalho pode contribuir significativamente, seja em suprir necessidades de informação de forma proativa, seja na organização de documentos pertinentes as práticas médicas, como entrada de dados em prontuários, ou ainda no auxilio e sistematização para produção de material bibliográfico com base em análises epidemiológicas ou estudos de casos".

$>$ "publicação seriada com discussão sobre temas relevantes e de momento junto com uma revisão bibliográfica atualizada, nos moldes do INFOSAUDE. Aplicativos para celular com alertas sobre os assuntos importantes para o médico também seria um serviço valioso".

$>$ "pesquisas específicas oriundas de demandas determinadas, é possível oferecer vários serviços como: disseminação seletiva da informação (DSI), conforme perfil de cada profissional; informativos elou boletins de alerta temáticos; divulgação de sumários correntes".

$>$ “disseminar a importância do bibliotecário através do site da instituição, dado a importância da profissão. E também para o conhecimento dos outros profissionais, pois muitas vezes eles desconhecem a existência deste serviço na instituição para ajudar e orientar nas aulas e grupos de estudos existentes na residência médica e de enfermagem, e consequentemente para a capacitação de todos os funcionários existentes (educação permanente) em um ambiente hospitalar, que poderiam utilizar deste serviço para reciclagem e treinamento de desenvolvimento das capacidades laborais ligadas ao setor de saúde".

- como o bibliotecário se vê dentro da equipe médica/saúde:

$>$ "desconhece a atuação do bibliotecário dentro de uma equipe médica ou como assistente de pesquisa ou mesmo como organizador de documentação/informação orientada ao atendimento de profissionais da área médica. Penso que seriam atividades customizadas em função das necessidades, carga de trabalho $e$ disponibilidade de tempo dos médicos".

$>$ "o reconhecimento social do profissional bibliotecário é complexo porque nem sempre é ele quem ocupa posições de liderança na área, entretanto não é considerado um profissional de importância".

> "o bibliotecário na maioria das vezes não é valorizado pois lhe falta preparo, estudo, capacitação específica. Quando o profissional está adequadamente capacitado ele é muito valorizado pelos médicos no Brasil. A sua atuação na equipe médica não é uma prática no Brasil, mas seria muito importante e otimizaria o trabalho dos médicos e com certeza auxiliaria na melhoria da saúde da população atendida"

$>$ "considero a atuação do bibliotecário indispensável dentro de uma equipe médica e dentro de toda e qualquer equipe de trabalho porque informação está presente em todas as áreas".

> "o bibliotecário, em geral no Brasil, é muito relativo, ele espera uma demanda para então executar uma ação. Na minha visão, o bibliotecário precisa ampliar seu papel tecnicista e atuar como um gestor e estrategista. Não ser um mero prestador de serviços, ele deve interagir diretamente com a equipe médica, antecipando demandas, sendo seletivo na disseminação de informações científicas, alinhado com as especialidades médicas da unidade".

$>$ "facilitaria a pesquisa e orientação na procura de temas especificos". 


\section{- buscar e organizar informação científica relevante e pertinente faz parte do}

\section{trabalho em equipes dos médicos/saúde:}

$>$ "Não" e que "precisa de profissional para realização dessas atividades e o bibliotecário e uma excelente opção".

$>$ "o bibliotecário, principalmente em uma tão especializada função e tem como essencial a busca e organização de informações relevantes e pertinente, pois isso faz parte de seu metier (ofício). O médico tem em seus princípios éticos tratar seus pacientes da melhor forma possivel e os melhores tratamentos existentes, e para isso precisa estar informado quais são os melhores medicamentos e tratamentos para seus pacientes. Enquanto o bibliotecário tem como seu objeto a informação em todos os suportes, nesse contexto o papel do bibliotecário é suprir informacionalmente o médico com as melhores e mais precisas fontes, para ajudar em sua tomada de decisão

> "a organização de informação para uso pessoal e profissional é um imperativo para qualquer atividade, bem como para atualização profissional. Entretanto, a informação científica, e diria também tecnológica, é fundamental para a qualidade do exercício profissional do médico, benefícios para o paciente e equipe de trabalho"

$>$ "com toda certeza e não somente na área médica. A falta de acesso e não atualização de conhecimentos acarreta na redução da qualidade dos serviços prestados e, em alguns casos, gerando graves consequências, sobretudo na medicina"

$>$ "não tenho dúvida disso. O bibliotecário tem como seu objeto a informação, em qualquer suporte, enquanto o médico além de não disponibilizar de muito tempo para pesquisa, tem como seu objeto o tratamento de seu paciente. A interação melhoraria muito a eficiência se feita de forma seletiva com a disponibilização de informações relevantes de sua área de atuação e especialidade"

> "sim, pois antes de tudo a missão principal do bibliotecário é fazer a mediação entre a informação $e$ o conhecimento $e$ as pessoas (pesquisadores, profissionais, professores, estudantes, cidadãos). A formação do bibliotecário é essencialmente voltada para teorias, práticas e métodos orientados para o cumprimento de sua missão".

$>$ "sim, devido à experiência e dedicação a se manter organizado e atualizado o acervo atualiza o acervo de acordo com a demanda científica local. Função de educar e dissipar conhecimento atualizado e fidedignos com referencial teórico de confiabilidade científica. Garante a organização racional da instituição”."

> "é preciso avaliar o bibliotecário como especialista de informação científica em função do currículo e competências desenvolvidas durante a sua formação e, ainda, sua experiência profissional para indicar se sua atuação pode ser mais eficaz”.

No caso de informação em saúde e evidências médicas, é necessário maior conhecimento da área em saúde e das informações em geral da medicina e saúde. Pois, o 
conhecimento específico do bibliotecário acerca de informação em saúde ainda é ínfimo. Necessita-se de maior acuidade e ensino nessa área nas escolas de Biblioteconomia como eixo de formação e especialização. Os profissionais da informação e cientistas da informação acreditam que o bibliotecário possui perspectivas promissoras de ações na equipe médica/saúde. Contudo, requer maiores desafios a serem superados assim como a aquisição de nova formação e outras competências.

Por um lado, temos aspectos positivos no que tange a busca, pesquisa, organização e disseminação da informação. O seu trabalho nesse quesito é diferencial, eficaz e necessário tanto no ambiente médico, como em qualquer outro - científico, pessoal e profissional - onde esse profissional busca atender as necessidades informacionais e específicas de cada um. No apoio e busca de informações em saúde através do seu acervo e serviços informacionais criados e implementados para o suporte à tomada de decisão clínica e sobre diagnósticos dos problemas que afetam os pacientes. Foi demostrado também, que o bibliotecário deve valorizar-se e mostrando suas competências, habilidades e serviços onde quer que esteja inserido. Praticando o que mais sabe, tendo um perfil proativo, multidisciplinar em equipes de variados profissionais. Sem receio de agir nesses ambientes, pois, sua pouca integração com a equipe de multiprofissionais poderá tornar sua participação inexpressiva.

Por outro lado, os bibliotecários possuem grandes desafios de atualização e aquisição de novas competências e habilidades profissionais e pessoais. Em ampliar e mudar seu aprendizado e ação, longe do perfil tecnicista para um perfil proativo, integrador e diversificado. De interacionista, de agir comunicativamente e humanisticamente em qualquer ambiente onde trabalha e inclusive no ambiente médico. Fazendo com que os serviços informacionais atendem diretamente e antecipam as lacunas das necessidades informacionais tanto dos médicos quanto dos pacientes. Para isso, é necessário adquirir as competências necessárias para lidar com os aparatos tecnológicos, captação de serviços informacionais eficazes no ambiente dos hospitais, no tratamento, organização e seleção das informações, do acervo em saúde, o que requer novos conhecimentos da área da ciência médica, da linguagem e termos dentre outros.

Nessa parte, questionamos os médicos e profissionais de saúde, a saber:

- um médico que sabe estar informado age com mais segurança e tranquilidade no seu agir profissional e tomada de decisão? 
$>$ Todos disseram que sim. "a informação tem que chegar quase instantaneamente se não, não serve para apoio a conduta ambulatorial, nas urgências e emergências". E que o "profissional mais informado tem maior segurança no desempenho profissional".

$>$ "um bom embasamento técnico-científico é fundamental para a tomada de decisões clínicas e potencializa a segurança nas decisões".

$>$ " "a escolha de fontes informacionais - diante do volume".

\section{-qual é o lugar da informação científica na discussão de casos práticos?}

$>$ “a informação científica para a prática da medicina ocupa um lugar central, é a base principal para a tomada de decisões. Entretanto, percebo que há um conhecimento adquirido, compartilhado e vivenciado no cotidiano que acabam por nortear condutas clínicas".

> "atualização sobre diretrizes clínicas; composição de protocolos terapêuticos mais adequados à realidade dos serviços; comparação entre as diretrizes de diferentes especialidades médicas para análise de casos mais complexos; avaliação da viabilidade e da exequibilidade de diretrizes clínicas e protocolos previstos na literatura médica à realidade de redes locais de serviços de saúde; identificação da rede de (conflitos de) interesses na produção da informação científica"

- possuem tem tempo suficiente para pesquisar evidências médicas para cuidar 124 dos pacientes e diagnosticar:

$>$ Possuem pouco tempo e desejaria ter muito mais.

$>$ "durante os atendimentos considera que outra pessoa sem os conhecimentos médicos não poderia ajudar mais do que o próprio médico na busca da informação".

$>$ "a internet facilitou mas que demanda tempo".

$>$ "tempo hoje é algo que não se tem durante o cotidiano de trabalho. Com o volume de pacientes que trabalhamos e com a escassez de recursos e as metas de produção, raramente temos tempo para acessar um periódico científico, ler, avaliar a qualidade, verificar a força da evidência e tomar decisões. Fazemos isso na academia, nas pesquisas, num horário de estudo, se tirarmos esse tempo para isso, mas na prática cotidiana? No chão de hospital? Não, não temos tempo para isso".

$>\mathrm{Na}$ academia e não no Hospital.

- buscar e organizar informação científica relevante e pertinente faz parte do trabalho em equipes dos médicos? Quem faz esse trabalho na equipe médica/saúde?

> “não é uma prática padronizada, sendo mais uma iniciativa individualizada, do que coletiva".

> "ninguém de hábito. Como suporte para o trabalho de pesquisa acho extremamente válido a presença de um bibliotecário”. 
$>$ "com a chegada de uma dinâmica mais gerencialista ao processo de trabalho, a busca de informação, que antes era realizada pela equipe, passou a ser realizada de modos mais individualizado e com menor criticidade".

- o trabalho com informação científica pode ser mais eficaz se feito por um especialista:

$>$ "se tivéssemos um profissional só para nos ajudar na busca da informação, avaliar sua qualidade e socializar com as equipes seria muito bom”.

> "no caso de informação médica o profissional da informação necessitaria estar familiarizado com as especialidades temáticas do serviço”.

> "a ideia de suporte à busca por informação científica, feito por um profissional especializado, é sim uma estratégia que acredito poder imprimir maior eficácia ao trabalho com informação cientifica".

\section{- você médico incluiria um bibliotecário (profissional da informação) nas equipes}

\section{médicas nos hospitais:}

$>$ A maioria respondeu que sim

$>$ "a atuação de um profissional da informação na equipe traria mais agilidade $e$ refinamento no fluxo das informações cientificas".

> "incluiria não apenas pela expertise na busca de informação científica, mas pela potência que o bibliotecário tem de atuar em outros processos que implicam na visão ampla sobre informação em saúde, para além das buscas".

> "até incluiria, mas seria um processo complexo, principalmente na aceitação de um profissional não médico, e nem da área da saúde, para fazer parte da equipe, $e$ principalmente, pelo fato de que ele seria uma peça chave para a discussão clínica. As dúvidas sobre sua real função seriam extremas".

$>$ "sinceramente as deficiências de profissionais da área de saúde são tantas que dificilmente o bibliotecário seria prioridade”.

O cenário de agir do bibliotecário na equipe médica e de saúde no Brasil, por um lado, possui perspectivas promissoras para aceitação e inserção desse profissional nas equipes de saúde. No apoio às pesquisas e na procura de evidências médicas para tomada de decisão e diagnóstico; e ainda no apoio e assistência informacional aos pacientes. Auxiliando os médicos na questão das informações científicas, busca, organização e mediação, gerando dessa forma, mais tempo para os profissionais de saúde para cuidar dos pacientes de uma forma segura. Novas habilidades e competências serão requeridas do bibliotecário, para melhoria da comunicação, interação e relações humanísticas, conforme apresentado neste trabalho.

Por outro lado, fica demonstrado que se torna necessário esforços das autoridades para criarem políticas específicas para o sistema de saúde brasileiro. Visto que a realidade do 
sistema de saúde presente no cotidiano da população brasileira é de falta de profissionais de saúde, de escassez de recursos financeiros, de filas frequentes e de falta de leitos hospitalares disponíveis, de recursos materiais, de tecnologia de ponta para manter o serviço operando com eficácia para manutenção da população saudável. A apreciação do modelo do sistema de saúde canadense não se dá apenas pelo trabalho dos bibliotecários médicos na equipe, mas também pelo próprio sistema bem-sucedido como protótipo a ser seguido.

\section{Considerações Finais}

O modelo de sistema de saúde canadense tem obtido sucesso e vem se destacando no mundo todo. É um modelo que vem progredindo em rentabilidade organizacional e econômica, sem agravos, e principalmente no andamento dos processos de cuidados de saúde da população. E o bibliotecário contribui e faz parte desse rol de acontecimentos. Com a inserção desse profissional na equipe aumentaram as melhorias e qualidade da informação, tendo como ação e mediação o aprimoramento em acesso, busca e processos informacionais e comunicacionais, melhorias na busca quando há ausência de informação e de conhecimentos específicos sobre determinado assunto ou caso, sobre registros clínicos, evidências médicas e protocolos médicos, o que passou a aumentar as qualidades dos procedimentos e do atendimento ao paciente. Os profissionais de saúde passaram a ter maiores suportes informacionais e de conhecimento disponível para tomada de decisão - através dos serviços informacionais prestados e criados pelo bibliotecário médico - e o mesmo ocorreu com os pacientes quanto ao conhecimento sobre seu estado de saúde, passando eles a sentir-se bemacolhidos e seguros.

O fato de os médicos não dispor de tempo suficiente para atender os pacientes e concomitantemente pesquisar e buscar informações sobre um caso em particular ou casos em geral mostra a urgência, a importância e a necessidade do profissional do bibliotecário na equipe multiprofissional. O seu agir profissional e seu trabalho nas organizações de saúde estão contidos nas rondas médicas junto com os (as) multiprofissionais de saúde e médicos (as), o que envolve estar entre um leito e em outro junto com os pacientes, pesquisando e coletando informações para o preenchimento das necessidades informacionais e para o apoio ao diagnóstico do médico. Esse profissional alinhado na equipe médico-hospitalar procura atender as equipes e os pacientes. Seu trabalho é sair da biblioteca e estar nas equipes de saúde, o que implica mudanças pragmáticas e de paradigmas da profissão.

Com o exemplo e o modelo dos bibliotecários médicos canadenses e o agir desse profissional na equipe de saúde através de um rol de competências e habilidades para o 
trabalho com a informação, serviços informacionais em saúde e integrante na equipe, consideramos o protótipo inicial para alcançarmos melhorias e iniciativas valiosas. Com base na plataforma $H L W I K I$ criada pelo bibliotecário médico Dean Giustini, podemos constatar em um primeiro momento a junção da biblioteconomia tradicional com a biblioteconomia clínica, formando a "biblioteconomia incorporada", com um modelo e uma abordagem dinâmicos e engajadores dos bibliotecários na equipe de saúde. Dentre algumas funções registradas do bibliotecário médico podemos citar as ações sobre os processos de medicina baseados em evidências, a alfabetização de saúde, serviços de referências em saúde e revisão sistemática. Essas atividades devem ser guiadas sob a orientação de um profissional de saúde ou médico. O bibliotecário deve estar sempre acompanhado do médico do paciente que está no caso ou de outros profissionais de saúde, e em hipótese nenhuma ele deve diagnosticar ou ajudar a diagnosticar um paciente. A função do bibliotecário é buscar, coletar e disseminar as informações para o médico do paciente ou do caso em particular sobre a doença através do levantamento de evidências médicas.

Por outro lado, os bibliotecários encontrarão muitas dificuldades de inserção e aceitação na equipe médica pelo motivo de que ele ainda não está apto a agirem ambientes junto com os médicos e de que ainda não possui os conhecimentos necessários para agir com segurança dentro da equipe de saúde, isto é, pela falta de capacitação específica, o que é compreensível nesse caso. E também pela dificuldade de reconhecimento como profissional competente para estar nesses ambientes fora do tradicional e por ele ainda precisar fazer um esforço para ser conhecido e reconhecido tanto da função como nas suas competências e habilidades.

Os especialistas profissionais de saúde e os médicos já aceitam e incluem bibliotecários na equipe médica, defendendo que a informação científica e a busca de evidências médicas feitas por um profissional da informação serão mais eficazes e de melhor qualidade do que se forem conduzidas por outro profissional. Devido também ao imperativo de que esses profissionais possuem pouco tempo para realizar pesquisas mais amplas e profundas sobre determinado tema ou caso, podendo essa falta de tempo acarretar erros medicinais e levar à perda de vidas.

Outra dificuldade do bibliotecário na equipe médica está no fato de ele não ser formado na área médica, o que pode resultar em certos atritos. Mas que nada impede que o aprendizado e o ensino especializado na área seja corrigido, permitindo que o bibliotecário seja aceito como integrante na equipe médica. Por fim, devido ao fato de o sistema de saúde brasileiro estar passando por condições instáveis, os especialistas acreditam não ser prioridade 
a inclusão desse profissional na equipe, mesmo com os imperativos de melhorias nos processos e atendimento de saúde, bem como no desenvolvimento organizacional.

O trabalho com a informação em saúde é uma forma de cuidar da saúde do paciente. Os processos e serviços informacionais para atender os profissionais de saúde e os pacientes visam trazer alguma forma melhorias no andamento cirúrgico, em leitos dos hospitais e no acolhimento em uma hora de dificuldade. A mediação da informação relevante e de qualidade em cada caso pode atenuar as aflições ligadas a esse momento e permitir fazer de um bom trabalho informacional que pode salvar vidas. Por isso, acreditamos ser importante admitir e compreender as relações multiprofissionais na equipe de saúde, dentre eles, o bibliotecário como mediador da informação em saúde, criador e aperfeiçoador dos serviços informacionais, dessa forma, esse profissional é o elo de ligação entre a informação científica, com as práticas do dia a dia e a socialização, intensificando as práticas sociais e comunicativas: para o bemestar emocional e físico do paciente e na qualidade dos serviços dos profissionais de saúde.

\section{REFERÊNCIAS}

CIOL, R.; BERAQUET, V. S. M. Evidência e informação: desafios da medicina para a próxima década. Perspectivas em Ciência da Informação, v. 14, n. 3, p. 221-230, set./dez. 2009. Disponível em: <http://portaldeperiodicos.eci.ufmg.br/index.php/pci/article/view/775/ 644>. Acesso em: 12 jun. 2016.

FARRELL, A.; MASON, J. Evaluating the Impact of Literature Searching Services on Patient Care Through the Use of a Quick-Assessment Tool. Journal of the Canadian Health Libraries Association, v. 35, n. 3, p. 116-123, 2014. Disponível em: <https://ejournals. library.ualberta.ca/index.php/jchla/article/view/23476/17700>. Acesso em: 31 mar. 2017.

FLYNN, M. G.; McGUINNESS, C.; Hospital clinicians information behaviour and attitudes towards the 'Clinical Informationist': an Irish survey. Health Information and Libraries Journal, 2011. Disponível em:< https://cora.ucc.ie/bitstream/handle/10468/882/MGF_ HospitalAV2011.pdf? sequence=1\&isAllowed=y > . Acesso em: 22 mar. 2017.

GIUSTINI, D; CHO, A. Web 3.0 and health librarians: an introduction. Journal of the Canadian Health. v. 29, 2008. Disponível em: <https://www.researchgate.net/profile/ Dean_Giustini/publication/291205075_Web_30_and_health_librarians_an_introduction/links/ 56a13b3408ae984c4498d7dc.pdf>. Acesso em: 02 ago. 2016.

GOMES, H. F.; VARELA, A. V. Mediação da informação na área da medicina: possibilidades de interlocução entre os saberes científico, profissional e sociocultural. Perspectivas em Ciência da Informação, v. 21, n. 1, p. 3-22, jan/mar. 2016. Disponível em: <http://portaldeperiodicos.eci.ufmg.br/index.php/pci/article/view/1529>. Acesso em: 22 nov. 
2016.

HLWIKI INTERNATIONAL: History of health care in Canada, 2015. Disponível em: <http://hlwiki.slais.ubc.ca/index.php/History_of_health_care_in_Canada>. Acesso em: 13 dez. 2016.

HLWIKI INTERNATIONAL: Health libraries, 2015. Disponível em: <http://hlwiki.slais.ubc.ca/index.php/Health_libraries>. Acesso em: 07 set. 2016.

HLWIKI INTERNATIONAL: Reference services, 2015. Disponível em: <http://hlwiki.slais.ubc.ca/index.php/Reference_services>. Acesso em: 10 dez. 2016.

HLWIKI INTERNATIONAL: Systematic review searching, 2016. Disponível em: <http://hlwiki.slais.ubc.ca/index.php/Systematic_review_searching>. Acesso em: 09 set. 2016.

HLWIKI INTERNATIONAL: The role of health librarians in systematic reviews, 2016. Disponível em: <http://hlwiki.slais.ubc.ca/index.php/The_role_of_health_librarians_in_ systematic_reviews >. Acesso em: 18 dez. 2016.

HLWIKI INTERNATIONAL: Top Ten Competencies in Medical Reference, 2015. Disponível em: <http://hlwiki.slais.ubc.ca/index.php/Top_Ten_Competencies_in_Medical _Reference>. Acesso em: 11 dez. 2016.

HLWIKI INTERNATIONAL: Consumer health information, 2016. Disponível em: <http://hlwiki.slais.ubc.ca/index.php/Consumer_health_information>. Acesso em: 14 nov. 2016.

MARSHALL, J. G. et al. The value of library and information services in patient care: results of a multisite study. Journal of the Medical Library Association, 2013. Disponível em: <https://www.ncbi.nlm.nih.gov/pmc/articles/PMC3543128/pdf/mlab-101-01-38.pdf>. Acesso em: 22 mar. 2017.

ROSS-WHITE, A. Librarian Involvement in Systematic Reviews at Queen's University: An Environmental Scan. Journal of the Canadian Health Libraries Association, v. 37, n. 2, 2016. Disponível em: <https://ejournals.library.ualberta.ca/index.php/jchla/article/view/ 26149/20683>. Acesso em: 28 mar. 2017.

SOLLENBERGER, J. F., HOLLOWAY, R. G. The Evolving Role and Value of Libraries and Librarians in Health Care. JAMA: the journal of the American Medical Association, 2013. Disponível em: <http://list.uvm.edu/cgi-bin/wa?A3=ind1402\&L=PRIMO-LIST\&E=base64\& $\mathrm{P}=35218 \& \mathrm{~B}=--$ 006_AC08BA3AD2DE614B82E6335A5E2F560D3EE30CCFMED18 ameduvm_\&T=application\%2Fpdf;\%20name=>. Acesso em: 22 mar. 2017.

ZIPPERER, L. Clinicians, librarians and patient safety: opportunities for partnership. Quality \& safety in health care, 2003. Disponível em: <https://www.ncbi.nlm.nih.gov/pmc/articles/ PMC1743840/pdf/v013p00218.pdf>. Acesso em: 22 mar. 2017. 